\title{
What if form was the aid? Possible opportunities for renewed neighbourliness in aid relationships
}

\author{
Kabini Sanga \\ Victoria University, kabini.sanga@vuw.ac.nz
}

For Pacific Islands' peoples, relationships are of enduring importance. Yet, in spite of decades of aid giving and receiving, relationships in Pacific aid communities have predominantly been indifferent. In an era of global challenges, a new Oceania Education aid community is called to journey together to the common good through relational generosity. This call is based on the premise that people relationships constitute the glue that binds communities. The paper offers for consideration, three opportunities for the Oceania Education aid community to explore.

Keywords: aid relationships, form, modality, partnerships, neighbourliness, Oceania

\section{INTRODUCTION}

Drawing on the broad theme of strengthening relationships, this paper focuses on educational aid relationships and particularly on the forms of aid. After briefly surveying what is typically meant when aid forms are referred to, it identifies key areas of debate and interest within the literature on aid modality. It maintains that within these key areas, modality is seen as largely theoretical. Also argued is that the associated literature relies heavily on donors' views as against recipients' experiences. Because of the belief that it is people who give life to form, however, this paper offers an alternative perspective by focusing on form at the people level. Within this focus, the paper closely examines aid givers as opposed to the receivers of aid. Adopting a storytelling approach as a genre that enables the complexities of form at the people level to be lived with, the remainder of the paper is organized into three parts: brief observations about form as aid at the micro level; a good news story to illustrate that within constraining environments we can create hope-filling visions; and opportunities for a new Oceania Education community to consider.

\section{A BRIEF OVERVIEW OF AID MODALITY}

When talking about form we would typically think about such aid forms as core budget (Swedish International Development Agency [hereafter, SIDA], 2006), debt relief, cofinancing, trust funds, grant funding, Sector Wide Approach (Foster and Fozzard, 2000), the project (Foster and Leavy, 2001), the consultant or the Technical Assistance (NZAID, 2008), and so on. As forms of aid, these instruments have received broad scrutiny in the global literature over recent decades. Some authors (Burnside and Dollar, 2000; Easterly, 2003; Paul and Vandeninden, 2012) have pointed out the ineffectiveness of aid forms. Others (Duflo and Kremer, 2008; Banerjee, Duflo, Cole and Linden, 2007) have argued in favour of positive effects of aid forms. In-between these quite polarised positions, others (Cordella and 
Dell'Ariccia, 2007; Jelovac and Vandeninden, 2014) have pointed out the terms under which certain aid forms are effective or ineffective. In other words, the debate on aid modality and effectiveness is complex, general, inconclusive, and continuing.

A closer examination of the literature on aid modality shows five key areas of interest. First, aid modality is value-laden, hence political (Swedish Agency for Development Evaluation [hereafter, SADE], 2007). Within any aid approach are different actors, all with their different objectives and preferred ways of working. As well, according to McGillivary (2003), where donors have historical relationships with recipients, these often influence the modality used. Moreover, modality is context-, path-, and sector-dependent (SADE, 2007), and is readily influenced by incentives (Gibson, Andersson, Ostrom and Shivakamar, 2005). The political nature of modality is further enhanced by the absorptive capacities (Rose, 2009) of both donors and recipients.

Second, aid modality is donor-driven. According to the The Paris Declaration for Aid Effectiveness (High Level Forum, 2005), while the rhetoric is that partner countries determine the preferred aid forms, the reality is that donors select the forms of aid. In agreement, Hirst (2005) noted that this is so because of donor agendas and preferences. As well, donors set modality decisions because they are influenced by international declarations such as the Paris Declaration on Aid Effectiveness of 2005 and, more recently, the Global Monitoring Framework (Global Partnership, 2013). Further, donor choice of modality is also determined by policy guidelines as with NZAID (NZAID, 2008) and AUSAID (Hirst, 2005).

Third, aid modality is characterised in a number of ways. According to Foster and Leavy (2001), modality is described by recipient obligations in terms of conditionality, earmarking, and accountability; thereby placing General Budget Support at one end and projects through Non-Government Organizations at another. In another typology, NZAID (2008) used three categories: higher order modalities, contestable modalities, and project modalities; with the clear view that higher order modalities such as pooled funds, sector support, and strategic partnerships were preferred. In a final example, Martens (2004) categorises modalities into a complex web of hierarchical relationships between principals and agents as actors. In this categorisation, one party (principal) gives instructions to another party (agents). At the next level down, the agent becomes a principal; giving further instructions to other agents.

Fourth, aid modality is linked to a relational framework within which a system of incentives exists. In the Swedish Development Agency for instance, a formal decision-making structure and procedures govern aid modality. According to SADE (2007), within the Swedish partnership framework, multiple policy actors such as the parliament, government departments, agencies, civil society, and private sector partners, exist and exert influence on modality. As stated, it is the principal-agent relationships which are at play within such a setting. From an incentive perspective, the interactions and exertions of influence take place at the systemic, organisational, and individual levels (SADE, 2007). It is at the individual level that moral hazards or hidden action (Martens, 2002; Ostrom, E,. Gibson, C,. Shivakamar, S. and Andersson, K., 2002) potentially exist.

Fifth, from the mid-2000s there has been a shift in aid modalities which has been heavily driven by technocratic and bureaucratic ideological changes. Many authors (for example, Holvoet, 2010; Jelovac and Vandeninden, 2014) have observed that donors have shifted from project aid to budget support. Particularly in multilateral aid as compared to bilateral aid, this shift of modality has been more noticeable (Clist, Isopi, Morrissey, 2012). A counter view to this has been expressed by Hirst (2005) who noted that the supposed change is more about donors relating to each other rather than any fundamental aid form transformation. 
From this brief overview of the modality literature, it is obvious that aid form is not seen as the aid; rather it is the means by which donors offer and recipients receive aid. As well, form is seen as systemic, structural, organisational, and about physical arrangements and activities, a view which emphasises the 'bricks' in a 'bricks and mortar' sense. An obvious effect of this privileging is that the level of relationships - between people - is neglected. The literature also shows that form is named, administered, evaluated, and changed by donors; reinforcing the power relationships entailed in the 'bricks' conceptualisations of form. Finally, according to Killick (2004) the literature on modality is largely theoretical and relies heavily on donors' views as against recipients' experiences.

\title{
FOCUS, CAVEATS, DEFINITIONS, POSITIONING, STRUCTURE
}

Given the above theoretical-conceptual landscape, this paper offers an alternative perspective premised on the belief that it is people who give life to form; thus it focuses on form at the people level. Within this focus, the paper closely examines aid givers as opposed to the receivers of aid. Despite this focus on aid givers, my concluding observations are intended for both givers and receivers of aid. Throughout the paper, I use the plurals we and our to acknowledge that - as a New Zealand tax payer (therefore a contributor to the official New Zealand aid programme) and an active donor consultant and Technical Assistant (TA) - I see myself as part of the donor community. My observations in this paper are based on insights from my three decades of being an actor in multiple roles and jurisdictions within the aid industry. I use a storytelling approach as this genre permits us to live with the complexities of form at the people level without the need for quick resolutions, premature disbandment, or disengagement with each other.

As a backdrop to this tok stori (talanoa, conversation), I concur with others (such as Bruggemann, 2010) that Oceania is not exempted from the global crisis of the common good facing humanity. In the Pacific region, this crisis is evidenced by sparseness (of health services, the high costs of living, etc.), scarcity (of text-books and teachers in schools), and a culture of anxiety. Some would say Pacific peoples, like those elsewhere, are living a wilderness existence where powerful forces are working against the common good of solidarity and common destiny. Against such a backdrop, my basic message is a call for a new neighbourliness - a new Oceania wantok system - one which invites all of us to reach beyond ourselves, beyond our private interests, and beyond our sectarian positions and passions.

What follows in this paper is organized into three parts: first, I make brief observations about form as aid at the micro level; second, I share a good news story to illustrate that within constraining environments we can create hope-filling visions; and third, I conclude with three opportunities for a new Oceania Education aid community to consider.

\section{MICRO-LEVEL OBSERVATIONS OF AID AS FORM}

\author{
"The form of our aid is itself aid... for form itself is an act of power" (source \\ unknown)
}

In elaborating on the quote above, I make four observations on the modus operandi of our aidgiving to Pacific Islands countries. The first is that our modus operandi assumes that we (givers of aid) have embedded within our aid policy a saviour-mentality message which we must get across to the recipients of our aid. From Wellington or Canberra, we design consultation visits or environment scanning studies to be undertaken in our aid recipient countries. These study 
visits are premised on our initiated policy messages on varied topics such as literacy, outcomesbased curriculum, school leadership, and/or diabetes or smoking; or as policy approaches such as SWAps, whole-of-government, and other modality rhetoric. We confidently legitimise these policy messages as underpinned by best practice, evidence-based research, progressive development, and/or good governance. Rarely are the policy messages initiated or specifically requested by our recipient countries.

Further to the above, I note that we (aid givers) are the conveyors of the message "we are your saviours. You (aid receivers) depend on us and on our help." As consultants, we are the drivers of aid form (Foster and Leavy, 2001). Typically, we express such a message through our requests for appointments with aid recipient country officials. We set out travel dates which are suitable for us. We request for meeting times based on our schedules. At times, we might even arrive in-country on a Saturday and request our local counterparts for a briefing meeting on a Sunday, disregarding that in the Pacific Islands, islanders do not 'work' on Sundays. Further, we express such a message in the questions we pose to the recipients of aid. We ask: Would your school benefit from this and that resource? Will your department need such and such capacity support? Do you need a TA for this or that project? Of course, to such questions, the only answer is, "yes." Moreover, we also express such a message in the terms of the Memorandum of Understandings that we draft and sign with our aid recipients. Consistently, such agreements are based on our laws; their conditions are always to protect us, and their requirements are based on our conventions and practices. Finally, our reporting, monitoring, and accountability systems are entirely self-serving and donor-centric (Tilley and Tavakoli, 2012). In other words, they are off-budget (Dijkstra, 2013). We (aid givers) commission the reports (SADE, 2007). We determine the what and how of the reporting. We ascertain the accountability terms and criteria (OECD/DAC, 2005) and the value propositions (NZAID, 2008).

My third observation is that our modus operandi privileges and prioritises speaking over listening, typified at the systems level by the dominance of donor voices in the literature on modality (Tilley and Tavakoli, 2012). In doing so, we are telling people (aid recipients) the solutions to their problems. Few people like being told. Few people delight in being treated as if they had nothing or little to contribute. Our (aid givers) attempts at listening (to allow their conversations) are often artificial and slightly contrived. We often show little desire to genuinely listen to the other, perhaps because we believe we have little to learn from the other. It is no wonder that our TA advice (in the form of reports) is, as a visit to any Pacific Ministry of Education storage room will show, gathering dust in aid recipients' offices.

My fourth observation on our modus operandi is that it emphasises clutter over people relationships. We emphasise activities. We call for meetings wherein we talk. We speak about outputs, outcomes, and results. The way we work, monitor, and report our work involves much clutter. We work hierarchically with our aid recipients.

Such aid is superficial because it works against the common good. Fundamentally, aid in its current form is based on assumptions of scarcity and a culture of anxiety. At the very least, if it is to achieve renewed neighbourliness, our aid must involve our entering into the cultures we are seeking to reach. It must involve our full effort to understand these cultures. Those who have experienced this aid form will tell us that such aid involves creating space within ourselves for the other. 


\section{A GOOD NEWS STORY}

Globally, the project is the least favoured form of aid (SIDA, 2007). The reasons for this are well-documented. Yet in many development agencies, including AusAID and the New Zealand Aid Programme, the project is the most used form (Hirst, 2005; SADE, 2007; Dijkstra, 2011). A further perplexity is that as a strategy for leader development within a project, the workshop is the least favoured approach. The workshop is deemed ineffective for leadership development. Yet, the workshop is the principal approach used in the Solomon Islands school leadership programme; a project of the Solomon Islands Ministry of Education which is administered by the Institute of Education of the University of the South Pacific.

During the first year of programme delivery, teams of two consultants were sent out to run fiveday workshops in 16 sites throughout the country. At the end of each workshop, in my capacity as the programme's strategic team leader, I would receive the post-workshop participant evaluation reports. A consistent message in the site reports was that participants wanted their paired consultants to return for the next workshop. For the next round of workshops, I changed the membership of teams. In this way, none of the earlier pairs of consultants were on a team together. Even so, the consistent message from the site reports remained unchanged: workshop participants wanted their pair of consultant trainers to return. "What is going on?" I asked myself. Solomon Islanders do not ask for project consultants to return as trainers! More so, as one who is familiar with the overwhelming opinions in the theoretical literature against the project and the workshop, I was surprised to see the consistent participant feedback from different sites over a period of a year. I asked myself: "What is this 'good' in a workshop strategy and within a project, the least favoured of aid forms?"

To answer the questions posed above, let me take you to East Mala'ita, Solomon Islands. Growing up on a small island in East Mala'ita in the 1960s and 70s, I had seen many young men leaving the village for Honiara or to the coconut plantations in Western Solomons in search of paid employment. As a young man said goodbye, often he'd promise an aunt or a mother, "Once I've earned money I'll purchase and send you a bush knife". Or as a young man stepped onto a dingy, in parting from an uncle or a father, the young man would say, "I'll send you money for the children's school fees". Or, he'd promise to send his uncle an axe. To such promises, the adults would typically respond, in true Gula'alā wisdom, moudi! In my growing up years, I had witnessed many village mothers, aunties, fathers, and uncles disappointed because their young adults had failed to keep their promises. Often this disappointment was eased only by their wisdom as reflected in their responses of moudi. What is moudi? Briefly, to the Gula'alā people of East Malai' ita, the concept of moudi refers to having a willing heart, to having a heart to help or a heart to serve.

To return to the good news story of the Solomon Islands School leadership programme, it is true that there were a number of variables explaining the credibility of the consultant teams. Chief among these reasons is that each consultant is seen as moudi — having a helping and serving heart.

\section{POSSIBLE OPPORTUNITIES}

What opportunities might be gleaned from this good news experience of aid relationships? 


\section{Family: interdependence, woven lives, a rich tapestry}

People of Oceania might consider a view which assumes that our lives have been and are woven together. This means that in Vanuatu, Tanna people cannot dismiss man Efate. Mainstream Australia must not think of Aborigional Australia as less gifted, minimally able or not having much to teach us. Mala'ita bigmen must not mindlessly assert our morality at the cost of dignity, justice, and compassion for women, children, and the weaker members of our communities. The Samoan matai (chief) or the Tongan cultural elite must not trivialise the dignity, contribution, and potential of the New Zealand/Australian-born, the part-other, and the diasporic Polynesian youth.

The point? We, peoples of Oceania, within our villages, on our islands, in our nation states, and our region, are family. In Samoan, we are aiga (family). To Tongans we are kainga (family). We are not just partners in development or colleagues in a college of professionals. We are wanefuta (relatives, as we say in Gula'alā). As family, we are travelling in the same vaka or canoe. Our lives are woven together.

The purpose (and challenge) of woven lives is to produce a rich tapestry of human experience; dignifying each one of our members, uplifting our human spirits to love as well as to cry with each other, and compelling us to give of ourselves in compassion, in our time. Such a view of woven lives requires a different model of exchange and of relationships. Such a model does not involve matching of gifts, comparing of abilities, blaming or abusing each other, or reducing human dignity.

\section{Hospitality}

In a relational sense, aid is fundamentally an act of hospitality, and of generosity. Supposing we strip away the media hype, the formal aid policies, the politics, the conditionality-and if we take down the signboards or we remove the name tags (donor partner, consultant, advisor, expert, facilitator etcetera), what are we left with? What remains is people giving to and receiving from each other. We are left with people being neighbourly to each other.

Seen as an act of generosity, aid is fundamentally risky. Recently, I was on the plane from Honiara to Brisbane and enjoyed an engaging conversation with two young people: an Australian Youth Programme participant who was returning home following a year's assignment in the Solomon Islands, and a New Zealand recent graduate on assignment with the Solomon Islands Civil Society. Both young people spoke passionately with me about their Solomon Islands experiences. They shared their stories about village life. They spoke with me about ideas which I was familiar with. One talked about daily-life stories involving members of my Solomon Islands family. This young person even addressed me in the Mala'ita language of my family members. In summary, both young people spoke about how much their lives had been challenged and changed by their Solomon Islands experiences. At that moment, my views too were changed by that brief encounter: I was beginning to appreciate the two young people as family.

What is the point of this story? Aid givers do not survive their mission intact. Like these young people, aid givers are changed by their missions. This is because generosity is a gracious spacegiving, requiring giving up of oneself for others. Understood this way, aid giving is challenging. Generosity is against-the-grain. It calls for a resolution. Are we prepared to be gracious in our space-giving in our aid relationships?

To help us in our further thinking about our aid relationships, might it be that we (aid givers) are changed by our encounters with aid recipients? Might it be that the flow of transformation 
is not one-way? Might it be that we also discover 'gifts' and or contributions from the experiences of the other?

\section{Middle ground: living on the edge by seizing the middle ground}

The Oceania Education aid community must not remain a club; secure in its self-referential notions of credibility. Our education community must be open to the outside. Being so allows us to be more easily drawn to unfamiliar and uncomfortable places. Only in such places will life be experienced in tension; where we are secure and yet are vulnerable. This is a tough call, particularly in a world and during an era of overwhelming challenges. But this is also a call of opportunity. Available for seizing is the opportunity for an aid community which fully engages in its time but is not fully accepted, welcomed, or settled in its world.

As an illustration, let me talk about the katukatu (a bait fish) and the mamula (trevally). The katukatu is a territorial school of fish that can be found near the beach in tropical climates. In the order of sea world survival, the katukatu makes good lunch for the mamula. So where there are katukatu, there are always mamula lurking around.

Growing up on an island, I have often watched a mamula coming beneath a school of katukatu. Mamula strategy is simple. Dive beneath the school of katukatu. Shoot up. Scatter the katukatu. One or two bait fish will wander off. Zero in on the wandered katukatu. Lunch. This same strategy, however, has a more positive effect on the school of katukatu. Whenever the school of katukatu senses the presence of mamula, the school of fish always huddles together, thereby settling into a more tight-knit community; making it harder for mamula attacks.

The point? The lesson of this fishing tok piksa (imagery) is to invite the Oceania Education aid community to be a disruptive presence in our time and in our region of the world. Like the mamula, it may be that we are unsettling the settled yet also settling the unsettled.

\section{CONCLUDING COMMENTS}

As stated, the forms of our aid giving and receiving remain theoretical and are heavily reliant on donor views. The experienced reality in Pacific Islands settings, however, is one marked by sparseness, scarcity, and anxiety wherein powerful forces against the common good seem prevalent. To counter these 'enemies' of the common good, I am calling for a new Oceania wantok system - an animation of neighbourliness which involves living beyond private interests, positions, and passions. Towards this call, the new Oceania Education aid community is asked: In our aid giving, are we willing to be truly changed by our encounters? Or are we merely recruiting more people to our ways of seeing the world (so we can feel secure in a larger population of people like us)? Rather intrusive and disturbing questions indeed. But what is at stake - surviving the onslaught on the common good-demands more from this new generation aid community. For us, our aid and life need to be open to that which is outside. Our relationships within Oceania must draw us to unfamiliar, uncomfortable places; the hinterlands and alien territories of our human existence and experiences. Such places are the opportunities wherein life is lived on the threshold; life is experienced in tension where we are known but yet unknown.

\section{REFERENCES}

Banerjee, A., Duflo, E., Cole, S., \& Linden, L. (2007). Remedying education: Evidence from two randomized experiments in India. Quarterly Journal of Economics, 47(2), 373-447. 
Bruggemann, W. (2010). Journey to the Common Good. Louisville: WJK Press.

Burnside, C., \& Dollar, D. (2000). Aid, policies and growth. American Economic Review, 90(4), 847-868.

Clist, P., Isopi, A., \& Morissey, O. (2012). Selectivity on Aid Modality: Determinants of Budget Support from Multilateral Donors, The Review of International Organizations, 7(3), 267-284.

Cordella, T., \& Dell'Ariccia, G. (2007). Budget support versus project aid: A theoretical appraisal, The Economic Journal, 117(523), 1260-1279.

Dijkstra, G. (2013). The new aid paradigm: A case of policy incoherence. (DESA Working Paper 128). New York: United Nations, DESA.

Duflo, E., \& Kremer, M. (2008), Use of randomization in the evaluation of development effectiveness. In W. Easterly (Ed.), Reinventing Foreign Aid (pp. 93-120). Cambridge, MA: MIT Press.

Easterly, W. (2003), Can foreign aid buy growth? Journal of Economic Perspectives, 17(3), 23-48.

Foster, M., \& Fozzard, A. (2000). Aid and Public Expenditure: A Guide. (Working Paper 141). London: Centre for Aid and Public Expenditure, ODI.

Foster, M., \& Leavy, J. (2001). The Choice of Financial Aid Instruments. London: Centre for Aid and Public Expenditure, ODI.

Gibson, C., Andersson, K., Ostrom, E., \& Shivakamar, S. (2005). The Samaritan's DilemmaThe Political Economy of Development Aid. Oxford: Oxford University Press.

Global Partnership. (2013). Guide to the Monitoring Framework of the Global Partnership. OECD Global Partnership.

High Level Forum. (2005), The Paris Declaration for Aid Effectiveness. OECD/DAC.

Hirst, C. (2005). An Analysis of Aid Modalities and Identification of Innovative Approaches Utilised by AUSAID. Canberra: AUSAID.

Holvoet, N. (2010). Gender Equality and New Aid Modalities: Is Love Really in the Air? European Journal of Development Research, 22, 97-117.

Jelovac, I., \& Vandeninden, F. (2014). How should donors give foreign aid? A theoretical comparison of aid modalities, European Journal of Development Research, 26, 886-904.

Killick, T. (2004). Politics, Evidence and the Ne Aid, Development Policy Review, 22(1), 5-29.

Martens, B. (2004). Aid agencies and aid effectiveness. (Development Outreach Special Report), New York: World Bank Institute.

McGillivary, M. (2003), Modelling Foreign Aid Allocation: Issues, Approaches and Results, Journal of Economic Development, 28(1), 171-188.

NZAID. (2008). NZAID Guideline on Aid Modalities. Wellington: NZAID.

OECD/DAC. (2005). "Survey on Harmonization and Alignment of Donor Practices Measuring Aid Harmonization and Alignment in 14 Partner Countries," The DAC Journal, $6(1)$.

Ostrom, E., Gibson, C., Shivakamar, S., \& Andersson, K. (2002). Aid, incentives and sustainability: An institutional analysis of development cooperation. (SIDA studies in evaluation 02/01), Stockholm: SIDA. 
Paul, E., \& Vandeninden, F. (2012). Foreign aid transaction costs: What are they and when are they minimized? Development Policy Review, 30(3), 283-304.

Rose, P. (2009). Scaling-up aid to education: Is absorptive capacity a constraint? Prospects, 39(2), 109-122.

Swedish Agency for Development Evaluation. (2007). What determines the choice of aid modalities? (SADE Report). Karlstad: SADE.

Swedish International Development Agency. (2006). Sida's Statistical Handbook. (SIDA Report), Stockholm: SIDA.

Tilley, H., \& Tavakoli, H. (2012). Better aid modalities: are we risking real results? (ODI Report), London: Overseas Development Institute. 